\title{
Las conmemoraciones en la prensa escrita. Un análisis de las notas de Clarín y Página/12 sobre Cromañón (Argentina)
}

Laura Codaro ${ }^{1}$

\begin{abstract}
Resumen
El presente trabajo busca indagar algunos aspectos de las conmemoraciones de Cromañón, el incendio ocurrido en la Ciudad Autónoma de Buenos Aires (Argentina) el 30 de diciembre de 2004 que dejó 194 fallecidos y miles de sobrevivientes, en la prensa escrita local. Se intenta mostrar puntualmente cómo los diarios dan cuenta de los actos pero también producen insumos para recordar. Para ello se conforma un corpus de artículos periodísticos publicados en Clarín y Página/12, dos importantes diarios nacionales ideológicamente opuestos, los días 30 y 31 de diciembre desde 2005 hasta 2014 y se procede a la lectura, la descripción y el análisis de los textos. Se realiza un acercamiento teórico a las conmemoraciones y luego se estudian, en primer lugar, las representaciones de los actos conmemorativos en cada uno de los periódicos y en segundo lugar, las herramientas que ellos producen para la construcción de memoria, en pos de recordar Cromañón. Finalmente, se exhiben las conclusiones y las reflexiones que surgen de este trabajo que sirven para continuar investigando en torno a éste y a otros acontecimientos trágicos contemporáneos.
\end{abstract}

Palabras claves: Cromañón; Conmemoración; Periódicos; Memoria.

\section{Introducción}

Cuando se habla de las conmemoraciones se piensa fundamentalmente en las formas de recordar un acontecimiento, cómo hoy, en un tiempo presente, una o varias personas agrupadas (o no) en un colectivo construyen y reconstruyen eso que sucedió en un tiempo pasado. A lo largo de la historia se conmemoraron las conquistas, las revoluciones y las guerras, pero hay cierto consenso en marcar los años sesenta como la etapa de circulación de los discursos de la memoria, que se intensificó en la década de 1980 en Europa y Estados Unidos cuando tuvieron lugar diferentes debates en torno al Holocausto, se crearon museos, se resignificaron los aniversarios, emergieron los testimonios, entre otros fenómenos que lo ubicaron notablemente en un espacio público globalizado (HUYSSEN, 2007). Esta “obsesión memorialística" de las últimas décadas también es evidente en el territorio latinoamericano, particularmente aquí interesa subrayar las diversas prácticas conmemorativas vinculadas a las dictaduras recientes de los países del Cono Sur, que afloraron hace unos años y que se

\footnotetext{
${ }^{1}$ Profesora en Letras y Profesora en Lengua y Literatura Francesas, egresada de la Universidad Nacional de La Plata donde está finalizando la Maestría en Historia y Memoria. Desarrolla tareas de gestión en la Facultad de Humanidades y Ciencias de la Educación (UNLP), se desempeña como docente en distintas instituciones educativas y participa en diversos proyectos de investigación que ligan la literatura, la prensa escrita y la historia reciente. E-mail: lauritacodaro@hotmail.com
} 
RELACult - Revista Latino-Americana de Estudos em Cultura e Sociedade

Revista Latinoamericana de Estudios en Cultura y Sociedad | Revue Latino-américaine d'Études sur la culture et la société |

transforman, cobran otros sentidos, a la vez que se relacionan con otras conmemoraciones contemporáneas. En esta instancia se propone indagar algunos aspectos de las conmemoraciones de Cromañón, el incendio desarrollado el 30 de diciembre de 2004 en un local del barrio de Balvanera (Ciudad Autónoma de Buenos Aires, Argentina), se intenta mostrar puntualmente cómo éstas aparecen en la prensa escrita, para ello se parte de que ésta da cuenta de los actos pero también produce insumos para recordar. Debido a que "las fechas y aniversarios son coyunturas en las que las memorias son producidas y activadas" (JELIN, 2002, p.245), se conforma un corpus de artículos periodísticos de Clarín y Página/12 publicados los días 30 y 31 de diciembre desde 2005 hasta 2014. Se trata de dos diarios de tirada nacional con tradiciones y estilos muy distintos: Clarín, fundado en 1945 por Roberto Noble, mantiene un estilo más tradicional y conservador; Página/12, creado por Jorge Lanata en 1987, conserva una impronta más moderna y progresista.

Es necesario destacar que este trabajo forma parte de una investigación mucho mayor en la que se analiza la construcción de Cromañón como "acontecimiento" en la prensa escrita argentina y las formas en que ésta conmemora. La misma contempla las publicaciones que salieron a la luz el día siguiente al incendio (fundamentalmente en las ediciones impresas) y luego las notas de cada aniversario hasta llegar al décimo. En dicho estudio se emplearon tres diarios de tirada nacional donde se observó tanto el texto como la imagen: se trató de Clarín, La Nación y Página/12. Por ello, la metodología de trabajo de este artículo así como algunas ideas y reflexiones, que también están presentes en otros materiales que funcionan como satélites de aquella investigación, está estrechamente vinculada a ese proceso de búsqueda, selección y análisis de las fuentes.

Para observar y analizar estos textos se propone inicialmente exponer la metodología de trabajo empleada y luego se estudian separadamente las representaciones de los actos conmemorativos en cada uno de los periódicos de las estrategias que forja cada medio gráfico para recordar el acontecimiento trágico. Finalmente, se presentan un conjunto de resultados y reflexiones.

\section{Metodología}

Aquí se pondera una metodología de análisis eminentemente cualitativa, aunque se destacan algunos aspectos propios de las investigaciones cuantitativas, como la revisión de la cantidad de apariciones de determinados actos conmemorativos. Se conforma un corpus de 83 notas que aparecieron solo en las ediciones impresas de Clarín y Página/12, por lo cual se dejan de lado las ediciones digitales dado que no se pueden visualizar de forma completa y en algunos casos no difieren del formato papel. Se seleccionan todos los artículos referidos a Cromañón 
RELACult - Revista Latino-Americana de Estudos em Cultura e Sociedade

Revista Latinoamericana de Estudios en Cultura y Sociedad | Revue Latino-américaine d'Études sur la culture et la société |

que fueron publicados el 30 y 31 de diciembre en el período 2005-2014, es decir, hasta cumplirse el décimo aniversario de la tragedia. Los mismos fueron consultados fundamentalmente en la Hemeroteca de la Biblioteca Nacional Mariano Moreno (CABA), se procedió a la lectura y, a través del escaneo de los mismos, se constituyó un archivo funcional a este estudio. En este texto particularmente se los presenta y se los describe atendiendo a los rasgos conmemorativos que poseen respondiendo, en mayor o menor medida, a éstas y otras preguntas: ¿cómo aparece Cromañón?, ¿qué actividades o actos se refieren?, ¿qué actores se mencionan?, ¿qué estrategias se emplean para recordar Cromañón? Sin embargo, aquí no se exponen los textos ni las imágenes en el cuerpo del trabajo dada la extensión del mismo y además, como se trata de un corpus muy amplio, la incorporación de algunas notas limitaría el abordaje más general que se propone en esta instancia. Por el contrario, se utilizan citas directas e indirectas de distintos artículos a modo de ejemplo.

Antes de mostrar la revisión de los artículos, se exponen un conjunto de ideas teóricas de distintos autores que permiten observar los vínculos entre la prensa escrita y los procesos de memoria. De este modo, se explica qué conceptos se tienen en cuenta a la hora de leer el corpus periodístico confeccionado a la vez que se exhibe (y se pone a disposición del lector, por qué no) un marco teórico posible para abordar las conmemoraciones de otros acontecimientos traumáticos y distintas formas de recordar de los diarios.

Posteriormente se procede a analizar de forma separada pero con una mirada compartativa las notas que publicaron ambos diarios en los aniversarios a lo largo de 10 años. Para un análisis más ordenado, se piensan, por un lado, las formas de representar los actos para recordar Cromañón y por otro, los modos en que los diarios conmemoran. En lo que concierne al primer punto, puede afirmarse que a grandes rasgos,mientras Clarín pondera las celebraciones religiosas y las notas oscilan entre la información relativa a la justicia y a las responsabilidades políticas, Página/12 presenta una pluralidad mayor de actividades, crónicas detalladas y exhaustivas de los actos y distintos análisis generalmente firmados por periodistas. En cuanto al segundo punto, se plantean las variadas y heterogéneas herramientas que elaboran los medios gráficos en pos de las memorias de Cromañón, las cuales parecen responder a distintos fines y lógicas periodísticas. Aquí se sostiene que mientras que Clarín presenta notas aparentemente ligadas al testimonio en un sentido amplio y complejo y, en menor medida, artículos de opinión que se anclan en otros acontecimientos como el proceso judicial, Página/12 concibe la conmemoración de Cromañón como la visibilización de las voces, las historias y las problemáticas de los sobrevivientes. Además, el análisis y las reflexiones exhaustivas sobre temas ligados a Cromañón, que se leen en las notas de opinión, 
RELACult - Revista Latino-Americana de Estudos em Cultura e Sociedade

Revista Latinoamericana de Estudios en Cultura y Sociedad | Revue Latino-américaine d'Études sur la culture et la société |

muestran formas de construcción de memoria que miran al futuro. Éstas y otras preguntas traerán diversas reflexiones al respecto.

\section{Análisis de las representaciones de los actos conmemorativos de Cromañón en Clarín y Página/12 y de las formas en que estos periódicos conmemoran la tragedia.}

Para un primer acercamiento a las conmemoraciones parece imprescindible partir de las ideas de Pierre Nora (1992), quien habla de "la era de la conmemoración" para tratar de explicar la relación entre el pasado y el presente, entre la historia y la memoria. Si bien sus postulaciones están ancladas en el bicentenario de la Revolución Francesa, de allí se desprende que hay una "obsesión conmemorativa" que distingue a una época, que se caracteriza por los distintos usos del pasado que se hacen en el presente y se concretan en actos organizados por grupos y colectivos. Entre las distintas interpretaciones que se hacen de su amplio trabajo, Paul Ricoeur (2008) señala las tensiones entre la idea de la conmemoración como lugar de memoria, que clausura de alguna manera la posibilidad de seguir reelaborando el pasado ya que está fija y las conmemoraciones se van transformando. Aquí, lejos de concebir el cierre de una época marcada por las conmemoraciones, que habla, a su vez, de una incapacidad de recordar y hasta de una memoria fosilizada, muerta, se propone pensar en una memoria viva que conduce a desarrollar una multiplicidad de prácticas de conmemoración que adquieren diferentes sentidos. Más aún, Henry Rousso (1987), otro de los teóricos del campo de estudio de la Historia y la Memoria, sostiene que las conmemoraciones son manifestaciones de la memoria colectiva (oficiales, nacionales, locales, partidarias), "vectores de memoria” que ofrecen implícita y explícitamente determinadas representaciones.

En América Latina y particularmente en Argentina, hay una pluralidad de estudios que se ocupan mayoritariamente de las conmemoraciones ligadas a los procesos de independencia y de las dinámicas escolares en torno a los "actos de memoria". Ahora bien, para pensar las prácticas conmemorativas de las últimas décadas, los trabajos de Elizabeth Jelin, que ciertamente consideran los postulados de los investigadores antes mencionados, resultan harto significativos. En uno de sus libros más reconocidos consagrado a este tema titulado Las conmemoraciones: Las disputas de las fechas "in-felices" (2002) propone observar los aniversarios y las fechas de conmemoración vinculadas a las dictaduras del Cono Sur. Explica que son prácticas sociales, "marcas" de las memorias sociales, rituales, calendarios y eventos de recordación que adquieren mayor importancia en las fechas conmemorativas, en las cuales es posible descubrir las tensiones, las continuidades, las fracturas, los cambios. Señala una 
RELACult - Revista Latino-Americana de Estudos em Cultura e Sociedade

Revista Latinoamericana de Estudios en Cultura y Sociedad | Revue Latino-américaine d'Études sur la culture et la société |

necesidad de "historizar la memoria", es decir, observar las transformaciones de las prácticas conmemorativas considerando distintas variables como los actores, los momentos, los espacios, etc. La compilación analiza comparativamente distintas conmemoraciones de Chile, Brasil, Paraguay, Uruguay y Argentina a través de trabajos escritos por autores de dichos países. De estos recorridos la socióloga señala aspectos compartidos ligados a las conmemoraciones que vale la pena recuperar: la participación de las generaciones más jóvenes en los actos donde se conmemoran eventos que no vivieron, de allí interesa ver cómo ellos se vinculan con el pasado, se posicionan y se comprometen; el tema de la justicia, ya que su ausencia es palpable en las conmemoraciones; el protagonismo del movimiento de derechos humanos y el rol menor de los partidos políticos y sobre todo del Estado.

Indudablemente, existen otros trabajos en esta materia que pueden resultar útiles, como el texto de la psicóloga chilena Isabel Piper Shafir (2013), donde plantea que las conmemoraciones tratan de resaltar determinados aspectos de los acontecimientos, los eventos y los fenómenos que mantienen unidos a una sociedad, que contribuyen a formar y mantener las identidades, "son una práctica de memoria constituida por estéticas, afectos, discursividad, políticas y normas" (PIPER SHAFIR, 2013, pp. 3-4). Comenta que son fundamentales para interpretar el pasado y entender las memorias, más aún, la institucionalizan. Otra propuesta hace Patricia Valdés (2004), quien en uno de sus trabajos estudia las representaciones y los actos de conmemoración sobre la dictadura y el terrorismo de Estado en Argentina, ya que intenta mostrar la vital importancia que tuvieron los organismos de derechos humanos en las "iniciativas de memoria", que ella entiende como lugares de aprendizaje. Explica que tanto las representaciones como los actos en sus plurales formatos favorecen la comunicación, el debate y la reflexión. En efecto, en muchas ocasiones se trata de testimonios, entonces se entabla una relación entre el que habla y el que escucha, lo cual sirve para pensar en el frecuente uso de la voz del testigo en las conmemoraciones.

En lo que concierne a los vínculos entre las conmemoraciones y los medios de comunicación, pueden distinguirse dos aristas centrales: en primer lugar, las diversas conmemoraciones que las personas organizan pueden ser nombradas, expuestas, compartidas en la prensa escrita; en segundo lugar, los diarios se conforman como "vectores de memoria" puesto que ellos también conmemoran los acontecimientos traumáticos de diversas maneras, generan insumos para recordar. En los dos casos se piensa en un vasto conjunto de publicaciones que salen a la luz sobre todo en los aniversarios y en algunas fechas puntuales para recordar algún acontecimiento (un día especial en el mes; el comienzo o la finalización de un proceso judicial; la Navidad u otra fecha con algún valor simbólico en particular, etc.). 
RELACult - Revista Latino-Americana de Estudos em Cultura e Sociedade

Revista Latinoamericana de Estudios en Cultura y Sociedad | Revue Latino-américaine d'Études sur la culture et la société |

Es interesante subrayar que no se hallan numerosas investigaciones que aborden esta cuestión, con excepción de algunos trabajos aislados. Entre ellos resulta pertinente mencionar la propuesta de Sonia Gladis Hucowsky (2016), quien se propone analizar desde la semiótica las conmemoraciones que realiza la prensa escrita en torno a la muerte de dos figuras argentinas: "Evita" y "El Che". La autora se centra en el análisis del discurso para pensar en los modos en que la prensa escrita cuenta recurrentemente la historia de estos dos "héroes" -como elige llamarlos. Si bien estas representaciones, manifestaciones y construcciones de los diarios intervienen de alguna manera en la memoria colectiva de una comunidad, sus producciones se concentran en exponer qué se cuenta y qué se muestra de la vida y la muerte de estos dos personajes.

Por otro lado, hay investigadores de otros países que reflexionan sobre la construcción de memoria en los medios de comunicación a partir de un caso local o específico. Así procede la brasileña Marialva Barbosa (2001), quien a partir del proyecto lanzado por la Red Globo Televisión para conmemorar los 500 años del descubrimiento de Brasil propone repensar las estrategias mediáticas para construir y recordar un acontecimiento. Vale la pena destacar que si bien se trata de un artículo publicado hace casi 20 años contempla cuestiones ligadas a la virtualidad, a la globalización y al alcance potencial que tienen las noticias, así como también a los intereses políticos, comerciales y lucrativos que envuelven a las conmemoraciones. Por su parte, desde Colombia, Jairo Enrique Martín y Jefferson Jaramillo-Marín (2014) presentan un trabajo que resulta iluminador en esta propuesta. Ellos parten de que la prensa escrita es un archivo de memoria que guarda acontecimientos disruptivos del pasado y del presente y luego desglosan algunas reflexiones teóricas sobre las representaciones de las conmemoraciones en los diarios. Su análisis de las noticias sobre la toma guerrillera de Mitú publicadas diez años después, muestra qué interpretaciones se legitiman y cuáles se opacan, qué voces se silencian y cuáles se recuperan. Resulta pertinente detenerse en sus conclusiones: finalmente sostienen que los artículos revisados presentan el acontecimiento violento de manera descontextualizada, que los textos cumplen una función meramente informativa y que los testimonios de las víctimas aparecen como un recuerdo más. Otro abordaje presenta la tesis doctoral de Sandra Fernández López (2012) que intenta demostrar, a partir del análisis de la prensa española en tres aniversarios del Estado de Israel, que los medios de comunicación no sólo son agentes que transmiten conocimientos sino que adoptan una postura ideológica determinada, que pretenden expandir a través de diferentes estrategias. Probablemente algunas de las ideas más interesantes que sobrevuelan su investigación se vinculan por un lado, a la influencia de los vínculos que el Estado tiene con aquello que se conmemora sobre 
RELACult - Revista Latino-Americana de Estudos em Cultura e Sociedade

Revista Latinoamericana de Estudios en Cultura y Sociedad | Revue Latino-américaine d'Études sur la culture et la société |

los medios de comunicación; por otro lado, a las prácticas que emprenden los periódicos para recordar en el presente.

Ahora bien, surgen algunas preguntas ¿cómo se conmemora Cromañón? y en este sentido ¿qué aportes realizan estas investigaciones para definir y pensar las conmemoraciones en torno al acontecimiento trágico? Como se ha visto, en el campo de estudio de la Historia reciente, las reflexiones en torno a las formas de conmemorar emergieron sobre todo después del año 2000. Siguiendo a Jelin que habla de las "marcas sociales de la memoria" asociadas a fechas y rituales, aquí es posible afirmar que las conmemoraciones de Cromañón representan un conjunto de prácticas desarrolladas mayoritariamente en los aniversarios, es decir, el 30 de diciembre de cada año (desde las vísperas con las vigilias, durante el día y sobre todo a la noche, dado que el incendio comenzó a las $22.50 \mathrm{hs}$ y prolongándose hasta la madrugada). No obstante, aparecen otras fechas significativamente importantes por los actos conmemorativos que se llevan a cabo como la Navidad, el cumpleaños de los jóvenes fallecidos en el incendio, el 30 de marzo de cada año que es el "Día en Homenaje a las víctimas de la tragedia de Cromañón" y fue incorporado en 2005 en el calendario escolar de la Provincia de Buenos Aires y de la Ciudad Autónoma de Buenos Aires, por mencionar las más sobresalientes. Se trata de prácticas de orígenes diversos que ocupan el espacio público, como la organización de las marchas, la exposición de carteles y pancartas con distintas leyendas, las muestras fotográficas, la reproducción de videos, las intervenciones artísticas, la presentación de grupos musicales, las celebraciones religiosas, la lectura de documentos colectivos, la instauración de memoriales, los murales, las actividades de concientización, entre otros actos que a lo largo de estos años se realizaron sobre todo en el santuario del barrio de Balvanera, en la Plaza de Mayo y en la catedral metropolitana que está enfrente, en la Plaza de la República donde se ubica el Obelisco y en diferentes puntos representativos de distintas zonas del Conurbano bonaerense. Estos actos conmemorativos recuerdan a las 194 personas fallecidas en el incendio y, en menor medida, a los padres de las víctimas fatales y a los sobrevivientes que murieron posteriormente de forma intempestiva (en algunos casos, por graves enfermedades irreversibles y suicidios), entonces, recuerdan la muerte injusta, la vida arrebatada y la ausencia. Por ello, salen a la luz un conjunto de acciones y discursos donde priman los sentimientos y las emociones. Los homenajes vuelven a lo que sucedió esa noche, a las causas y a las consecuencias del acontecimiento trágico, miran el recorrido de lucha y hacen referencia al pasado y al presente. Asimismo, en estos actos los agentes suelen mostrar su posicionamiento frente al resto de los actores involucrados en el episodio (los músicos, los empresarios, los funcionarios públicos, la Justicia, etc.). 
RELACult - Revista Latino-Americana de Estudos em Cultura e Sociedade

Revista Latinoamericana de Estudios en Cultura y Sociedad | Revue Latino-américaine d'Études sur la culture et la société |

Todas estas acciones son emprendidas, como marca Jelin, por personas involucradas con el acontecimiento trágico, en este caso tanto los familiares y amigos de las víctimas fatales, como los sobrevivientes y sus allegados, y otros grupos que se identifican con el colectivo que recuerda y pide justicia, que aquí son diferentes actores del ambiente del rock, agrupaciones políticas y sociales, familias afectadas en otros eventos trágicos, etc. En este sentido, diferentes investigadores se han interesado en el Movimiento Cromañón, entre ellos se destaca el antropólogo Diego Zenobi (2014) quien identifica a los familiares y a los sobrevivientes como víctimas que se ligan al incendio a través del dolor $\mathrm{y}$, como parte fundamental del movimiento, se organizan y se movilizan. La participación de todos estos agentes comulga con los aspectos generales que marca la misma autora en relación con las conmemoraciones surgidas de los procesos dictatoriales del Cono Sur. Asimismo, las ideas de Piper Shafir ayudan a explicar los vínculos que se establecen, por ejemplo, entre los familiares de los jóvenes fallecidos en Cromañón y la Asociación Civil Madres del Dolor, la organización Madres de Plaza de Mayo y Abuelas de Plaza de Mayo y otros grupos o personas afectadas por la pérdida de un hijo. Su participación en las conmemoraciones muestra las redes que estos colectivos tejen en la sociedad y resignifican el reclamo. Por otro lado, la incorporación del 30 de marzo en el calendario escolar como "Día en Homenaje a las víctimas de la tragedia de Cromañón" al igual que las numerosas actividades organizadas por el Movimiento Cromañón que se han desarrollado en estos casi 15 años en las escuelas, las universidades y otros espacios para reflexionar en torno a diferentes cuestiones ligadas al acontecimiento trágico, presentan a las iniciativas de memoria como un lugar de aprendizaje, utilizando las categoría de Valdez.

Ciertamente, hay trabajos que abordan las conmemoraciones en torno a Cromañón. Éstos conforman un escueto conjunto de investigaciones realizadas mayoritariamente por argentinos, que podría revisarse cronológicamente ya que los textos van dialogando entre sí. Para comenzar, Ludmila da Silva Catela (2008) reflexiona acerca de los vínculos entre la memoria y los derechos humanos en el contexto argentino y marca acertadamente los nuevos sentidos que adquieren los signos, los símbolos y otras formas de recordar a los desaparecidos de la última dictadura militar, que aparecen en diferentes acontecimientos ocurridos en democracia donde mueren jóvenes, entre los que destaca Cromañón. En esta publicación afirma que "los padres de Cromañón, por ejemplo, usan todo el sistema simbólico creado y consagrado por Madres y Abuelas (...)" (DA SILVA CATELA, 2008, p.17) y luego retoma y da lugar a dos cuestiones al menos controvertidas: por un lado, comenta la situación conflictiva de una parte del movimiento Cromañón con algunos integrantes de Madres de 
RELACult - Revista Latino-Americana de Estudos em Cultura e Sociedade

Revista Latinoamericana de Estudios en Cultura y Sociedad | Revue Latino-américaine d'Études sur la culture et la société |

Plaza de Mayo y de Abuelas de Plaza de Mayo; por otro lado, cuenta que recibió críticas y cuestionamientos por utilizar estas categorías para pensar fenómenos contemporáneos, frente a esto abre el debate -y cierra el artículo- con una pregunta, que es también una reflexión, acerca de los usos de la memoria.

Por su parte, María Luisa Diz (2010a) toma esta lectura de da Silva Catela y postula que las fotografías de la prensa masiva configuran Cromañón como un genocidio del terrorismo de Estado y analiza las representaciones sociales del pasado dictatorial en la configuración discursiva del acontecimiento trágico de 2004. Del mismo modo, en otro trabajo observa las características del santuario erigido en el barrio de Balvanera a través de las imágenes que aparecen en la prensa (DIZ, 2010b). Ciertamente éstos y otros artículos de la autora, que son fruto de una investigación mayor de la que resultó su tesina de grado titulada "Cromañón: configuraciones del pasado reciente y reelaboración de significados y prácticas”, muestran cómo la prensa masiva permite analizar el acontecimiento trágico y las formas de conmemorarlo.

Ahora bien, luego de definir de alguna manera las conmemoraciones de Cromañón interesa observar qué muestran los periódicos seleccionados, con tradiciones y estilos bien diferentes, de los actos conmemorativos que se llevan a cabo en torno a cada aniversario, observando las particularidades de cada caso y destacando luego los puntos de contacto y las diferencias. Como se anticipó, se procede a describir y analizar el corpus confeccionado para esta investigación que consta de más de 80 notas publicadas en las ediciones impresas de Clarín y Página/12, que vieron la luz el 30 y el 31 de diciembre entre 2005 y 2014.

En primer lugar, al observar los 40 artículos en relación con Cromañón que publicó Clarín en esas fechas, se afirma que la conmemoración ocupa un lugar preponderante ya que todos los años hay al menos una nota que hace referencia a uno o varios actos conmemorativos que se llevan a cabo con motivo del aniversario de la masacre. Estos artículos conviven, por un lado, con otros que también hablan de Cromañón pero no constituyen representaciones, reseñas o alusiones de actos de homenaje, éstos abordan temas vinculados a los juicios (el estado de las causas penales, las condenas, las posibles indemnizaciones, etc.), a la política (las decisiones, las declaraciones y las intervenciones de distintos gobernantes), a los tratamientos psicológicos y psiquiátricos (el estado de salud de los sobrevivientes y de los deudos, los análisis y las opiniones de distintos profesionales, etc.), a las responsabilidades y a los responsables de la masacre (cómo viven los músicos, los empresarios dueños y gerentes del local, los que ocupaban cargos políticos, etc.), a la situación de las víctimas y sus familias (las experiencias de pérdida, dolor y lucha de diversos 
RELACult - Revista Latino-Americana de Estudos em Cultura e Sociedade

Revista Latinoamericana de Estudios en Cultura y Sociedad | Revue Latino-américaine d'Études sur la culture et la société |

padres y sobrevivientes). Por otro lado, hay también otras múltiples noticias que en muchos números refieren a tragedias, a pirotecnia, a adolescentes y que son presentadas en la misma página o en la siguiente. Respondiendo a una política editorial, todas las notas ligadas a Cromañón que fueron publicadas en estos diez años se incluyeron en la sección "Sociedad", junto a textos que hablan de las altas temperaturas que padecen los porteños, de las vacaciones de verano y de las festividades de fin de año (Navidad y Año nuevo). Es necesario subrayar que la distribución de los artículos en el diario no es casual sino que forma parte de una práctica habitual pero no es la intención, en esta instancia, hacer un análisis macro de cada número. Para mostrar el tipo de textos que suelen rodear a los artículos sobre Cromañón, a modo de ejemplo, se puede mirar la edición impresa del 31 de diciembre de 2011, donde en la misma página en que se lee "Reclamos, a siete años de Cromañón" y hay una fotografía de la misa, se encuentra la nota principal titulada "El sobreviviente del kayak está en estado de shock pero evoluciona" y otra menor "Cuatro muertos en un triple choque". Junto a esta página de sucesos trágicos está la sección "Se me hace cuento" donde aparece el relato "El petardo" de Marcelo Birmajer, el cual, aunque no se vincula a Cromañón ni al resto de los acontecimientos fatales del diario, se desarrolla en la Ciudad Autónoma de Buenos Aires y menciona en su trama una única fecha exacta: el 31 de diciembre de 2005.

En una primera revisión es posible encontrar un grupo heterogéneo de conmemoraciones que podrían enunciarse de la siguiente manera considerando la frecuencia de apariciones: las celebraciones religiosas, las marchas, las actividades culturales y/o artísticas y las vigilias. Pensando en la conmemoración, podría hacerse una distinción entre los textos del 30 y los del 31 de diciembre de cada año. En el primer grupo, los homenajes nombrados son actividades que ya se estaban desarrollando, tal es el caso de la noticia del 30 de diciembre de 2010 que presenta la muestra fotográfica "Viví. Historias de Cromañón", que se había inaugurado días previos al aniversario en la Legislatura porteña; también se encuentran las vigilias que comienzan el 29 de diciembre, presentes en las notas de 2005, 2007 y 2008; otros artículos anuncian brevemente los actos conmemorativos que se van a desarrollar, sucedió así en 2005, 2006, 2007, 2008, 2009, 2010, 2013 y 2014. En el segundo grupo, se hallan los textos donde se cuentan las actividades que se desarrollaron, por ello interesa ver qué conmemoraciones se eligen nombrar y cómo se analizan en cada caso. Una de las principales observaciones a realizar en este subconjunto es la gran presencia de las celebraciones religiosas, en efecto, se contabilizan 10 notas que hablan primariamente de la misa que preside cada año el Arzobispado de la Ciudad Autónoma de Buenos Aires en la catedral metropolitana para recordar la masacre. Si bien las principales conmemoraciones que 
RELACult - Revista Latino-Americana de Estudos em Cultura e Sociedade

Revista Latinoamericana de Estudios en Cultura y Sociedad | Revue Latino-américaine d'Études sur la culture et la société |

reúnen a la mayor parte de los padres, sobrevivientes y otros actores del Movimiento Cromañón se inician con una vigilia en el santuario la noche del 29 de diciembre y continúan al día siguiente en Plaza de Mayo, con diferentes emprendimientos artísticos y culturales, el matutino destaca sobre todo la celebración religiosa que se realiza cada año a las 17, 18 ó $19 \mathrm{hs}$ en el templo porteño. Como parte del mismo ritual, luego de la misa la gente concentrada en la plaza emprende la marcha hacia el santuario del barrio de Balvanera, donde continúan y culminan los actos. En la misma línea, resulta significativo señalar que el interés del diario por el papel de la Iglesia Católica en el tema de Cromañón aumentaba progresivamente año a año. Esto puede demostrarse, por ejemplo, al mirar los diarios de 2007, 2009 y 2011 donde la nota central (por no decir la única) del 31 de diciembre sobre Cromañón se consagra a la conmemoración religiosa y presenta una fotografía que ocupa gran parte del artículo. Entre estos 10 artículos, algunos tienen grandes titulares y presentan fotografías tomadas durante la misa. Por un lado, suele resaltarse el papel desempeñado por el sacerdote, sobre todo cuando se trataba del entonces arzobispo de la Ciudad Autónoma de Buenos Aires, Jorge Bergoglio. Así, en la nota titulada “'Buenos Aires tiene que llorar y ser purificada por las lágrimas"” que ocupa casi toda la página y fue publicada el 31 de diciembre de 2005, se menciona, por ejemplo, que “[...] fue el mismo Cardenal quien favoreció y estimuló esa cercanía y esa naturalidad con una prédica llana, contenedora y solidaria." (Clarín, 31/05/2005, p. 53). En esa misma página hay una fotografía de la gente sentada en el piso de la catedral con los carteles y otra del cardenal saludando a una madre a la salida de la iglesia. En este sentido, importa notablemente el discurso del celebrante, sus afirmaciones en torno a las responsabilidades de la masacre. En efecto, en la nota ya citada del 31 de diciembre de 2005, se reproduce parte de la homilía donde Bergoglio sostiene que "Buenos Aires trabaja, hace negocios, busca rosca, pero no ha llorado aún lo suficiente. Ciudad distraída, dispersa, egoísta, casquivana, superficial..." (Clarín, 31/05/2005, p. 53). Asimismo, la nota "Críticas a Ibarra y a Kirchner en el segundo aniversario de Cromañón” del 31 de diciembre de 2006, aparecen algunas palabras pronunciadas por el obispo auxiliar Eduardo García sobre el enriquecimiento y los negocios que se realizan en la Ciudad, en el corazón de una noticia que no está centrada en la misa, como bien se puede suponer por el título pero que contiene, además, una fotografía de la misma. En la nota del 31 de diciembre de 2007, que dialoga con la recién citada, se titula "Buenos Aires aún 'no lloró' a Cromañón" también reproduce la crítica del cura a la sociedad y la necesidad del llanto y el duelo. En 2008, el obispo auxiliar Oscar Ojea presidió la celebración religiosa y el diario citó algunos fragmentos ligados al individualismo extremo de la sociedad y a la irresponsabilidad de los adultos, en un artículo 
RELACult - Revista Latino-Americana de Estudos em Cultura e Sociedade

Revista Latinoamericana de Estudios en Cultura y Sociedad | Revue Latino-américaine d'Études sur la culture et la société |

cuyo título es "Cromañón: misa y marcha a 4 años de la tragedia". Luego, en 2009, en "Bergoglio, duro con la Ciudad" la acusa de coimera, casquivana, superficial y vanidosa. En 2011 y 2012, también se reproducen las palabras del obispo Jorge Lozano en una escueta nota titulada "Reclamos, a siete años de Cromañón" y otra mayor "Cromañón: misas, fotos y globos para un homenaje menos amargo", respectivamente. Probablemente esta predilección del periódico por los representantes de la Iglesia Católica llegó a su punto máximo en 2013, año en el que Jorge Bergoglio fue elegido como Papa, así en el noveno aniversario de Cromañón, se publicó una nota que ocupaba toda la página y se titula "Cromañón: el Papa les escribió una carta a los familiares de las víctimas". Allí, ya no se retoma el discurso de Mario Poli, quien presidía esa misa, sino fragmentos de la carta enviada por Francisco a las familias, anunciada por el diario efusivamente: "Hasta ese momento esperó el obispo Jorge Lozano para hacerles saber la sorpresa a los presentes: el Papa Francisco le envió una carta que inyectó de emoción a los familiares presentes" (Clarín, 31/12/2012, p.28).

Clarín, además, en 2013 menciona someramente las actividades que realiza un grupo grande de sobrevivientes, algunos familiares de víctimas fatales y de sobrevivientes, amigos, simpatizantes del ambiente del rock y otros actores que piden justicia pero sostienen públicamente la inocencia del grupo de rock Callejeros, se trata de un colectivo autodenominado "No nos cuenten Cromañón". Esta conmemoración que se desarrolla hace varios años de forma paralela fue nombrada únicamente en la nota del 31 de diciembre de 2013, ya citada por la lectura de la carta del Papa Francisco durante la misa. Es posible percibir cierto contraste entre otros dos actos que protagonizan el artículo, no sólo porque en la primera parte se retoma el discurso cálido y solidario del sacerdote mientras que en la segunda parte -que se ubica en otra columna- se reproduce la voz de uno de los organizadores de "No nos cuenten Cromañón" criticando la venta de alcohol, sino porque además aparecen dos fotografías del mismo tamaño que probablemente no sean las más representativas de ambos actos pero que presentan, de alguna manera, dos formas opuestas de celebrar: la primera muestra a monseñor Poli dentro de la iglesia dando la bendición final a los familiares; la segunda, en cambio, muestra en primer plano la espalda desnuda de un hombre, de edad similar a la del cura, que posee un gran tatuaje que versa "Callejeros", con una multitud de fondo en las inmediaciones del Obelisco. Además, la primera foto es presentada como "recuerdo" pero la segunda como "en la piel", lo cual da a entender que no se trata de dos formas de recordar y que en el segundo caso llama más la atención la particularidad del individuo tatuado, que no es más que uno de los miles de asistentes al encuentro. Aquí puede leerse entre líneas la dicotomía sarmientina civilización/barbarie, representada en dos maneras 
RELACult - Revista Latino-Americana de Estudos em Cultura e Sociedade

Revista Latinoamericana de Estudios en Cultura y Sociedad | Revue Latino-américaine d'Études sur la culture et la société |

opuestas de conmemorar, que condice, a su vez, con la señalada estigmatización al ambiente del rock. En efecto, en la ponderación de la información relativa a la misa que ocupa el título y el copete de la nota, en las fotografías escogidas, en la presentación de las mismas y en el tratamiento de ambos actos puede observarse que se prestigia uno por sobre el otro, la misa por sobre el encuentro del Obelisco. Ciertamente, esto puede derivar en distintos análisis tanto de las conmemoraciones de Cromañón como de las representaciones de la prensa, pero acá es importante destacar que si bien los actos que se realizan paralelamente en la Plaza de Mayo y luego en el santuario y por otro lado, en el Obelisco congregan en cada caso a algunas personas o grupos que tuvieron más diferencias que enfrentamientos, aquí la construcción mediática opone sólo una parte del acto central de los aniversarios, es decir, la celebración religiosa, con la congregación en el Obelisco en su totalidad. No obstante, las mayores tensiones se produjeron, a grandes rasgos, entre un conjunto de familiares y otro de sobrevivientes, la Iglesia Católica, cuyos representantes no responsabilizaron al grupo musical Callejeros, se mantuvo al margen de esta suerte de disputa.

El diario Página/12 contiene 43 notas vinculadas a Cromañón en las fechas mencionadas en el período 2005-2014. Ciertamente, la presencia del tema es constante en las ediciones de cada aniversario, pero en lugar de haber una abundancia de notas que anuncien y reseñen los actos y las conmemoraciones, que es una práctica usual que busca informar, cuando el periódico decide contar las actividades que se desarrollaron, presenta notas extensas que funcionan como una crónica exhaustiva de los homenajes. En sentido estricto, cada nota es generalmente firmada por un periodista o cronista del diario, algunas de ellas hacia el final versan "informe". Estos textos comparten distintos rasgos: hay una enunciación donde predominan los tiempos del pasado; se presentan los actos de forma cronológica; se precisan datos sobre los lugares y los horarios; se explicita quiénes participaron tratando de individualizar a las personas y a los colectivos, desde las agrupaciones políticas hasta los que leyeron un documento o tomaron el micrófono en un acto en particular, se brindan los nombres y/o algún tipo de información personal relevante; se retoma directa e indirectamente parte del discurso de uno o varios participantes; se comenta lo que se percibe en relación con el ambiente que se generó y a los reclamos que se mencionaron; se analizan las situaciones se observan. Si bien no se usa la primera persona para narrar los acontecimientos, es posible descubrir la valoración personal de quien relata y las apreciaciones tan detalladas como particulares, el periodista que asistió, observó y escuchó todo, a través de un lenguaje sencillo y claro, de un vocabulario minuciosamente escogido, participa al lector de los actos y le cuenta su versión de los mismos. Este tipo de prácticas periodísticas, que representan más que 
una reseña, otorgan una interesante mirada explícita e intencionalmente subjetiva de las conmemoraciones que enriquecen la presencia y el desarrollo de Cromañón en los diarios. Los artículos de los ejemplares del 31 de diciembre de 2006, 2007, 2008, 2009, 2012 y 2014 conservan estas características. Es posible tomar uno de los más representativos que sirva como ilustración de lo que se acaba de detallar: la nota del 31 de diciembre de 2009 describe puntillosamente la marcha, su organización, su despliegue, sus participantes, lo que fue provocando, etc. Allí se lee:

\begin{abstract}
"El corte causaba la misma incomodidad que provocaría un corte piquetero. Pero a cambio de éste, la marcha por Cromañón no desataba el odio diferencial. Los automovilistas, es cierto, gesticulaban un poco, pero especialmente a las guardias de tránsito que se mantenían en su papel de corte e impedían el avance de los paragolpes. [...] Cuando la marcha se detuvo en Congreso, una madre muy joven le explicaba a su chiquito justo sobre la esquina de Entre Ríos, después de que el chiquito destapara la pregunta contundente de qué quieren." (Página/12, $31 / 12 / 2009$, p.15).
\end{abstract}

Como puede verse, más allá de las características de la movilización, en estas líneas se apela a las experiencias comunes de los automovilistas, que puede ser cualquiera de los lectores y se recupera, además, el diálogo entre dos participantes del evento, todo a través de un lenguaje sencillo y cercano. Evidentemente, éstas son percepciones agudas de un cronista atento y observador, que particulariza, de alguna manera, el relato de un acto conmemorativo que se repite año a año por Cromañón pero que también se vincula a otros homenajes que se despliegan en la urbe porteña.

Además, en estas notas se intenta destacar algún rasgo distintivo de esas conmemoraciones, algo novedoso que se emprendió en esa ocasión. Esto puede verse con claridad, por ejemplo, en la edición del 30 de diciembre de 2010 que contiene una nota sobre el Bosque de la Memoria, que es una iniciativa de los Amigos del Lago de Palermo, quienes plantaron 194 árboles para recordar a las 194 víctimas fatales, esta publicación acompaña al artículo central titulado "Un reclamo que se abre a otros reclamos", donde se cuenta cómo el Movimiento Cromañón estableció estrechos vínculos con otros damnificados y otras víctimas, tal es el caso de los familiares de Luciano Arruga, Martín Castellucci y la discoteca Kheyvis. De igual modo, se señala el "gritazo" en el texto principal del 30 de diciembre de 2013, el reclamo que realizaron los familiares frente a la puerta del local de Once.

Asimismo, este periódico identifica expresamente y da a conocer otro tipo de conmemoración que se llevó a cabo durante varios años, paralelamente a los homenajes que se inician en Plaza de Mayo y finalizan en el santuario: se trata de las actividades coordinadas por "No nos cuenten Cromañón". El 30 de diciembre de 2013, Página/12 presenta una columna titulada "Otros sobrevivientes" que hace referencia a este grupo y al día siguiente, 
RELACult - Revista Latino-Americana de Estudos em Cultura e Sociedade

Revista Latinoamericana de Estudios en Cultura y Sociedad | Revue Latino-américaine d'Études sur la culture et la société |

destina casi una página completa a contar estos homenajes desarrollados en las inmediaciones del Obelisco, en una nota titulada "En defensa de Callejeros". El texto principal sobre el tema del 31 de diciembre de 2014 "Cromañón, diez años, dos marchas" también señala la división en las conmemoraciones y los reclamos. No obstante, a diferencia de lo que sucede con otros grupos periodísticos, aquí no se busca hacer hincapié en la existencia de una rivalidad ni mostrar a través del relato ni de las imágenes un contraste marcado entre las partes, sino que se deja en claro que la distancia puntualmente reside en la postura que cada una adopta frente al conjunto musical Callejeros. En consecuencia, el hecho de que este medio gráfico mencione las características diversas de los actos da cuenta de que los homenajes no se reducen a una única actividad, por lo cual no se trata de hacer una mera reseña sino de analizar quiénes participan en cada caso, de qué modos conmemoran, qué los motiva, etc., esto implica, indudablemente, una mirada más atenta y un mayor conocimiento del tema.

Por otro lado, a diferencia de Clarín, aquí no hay un tratamiento especial y exclusivo de la celebración religiosa, no se publican notas que sólo hablen de las misas, de las declaraciones de Jorge Bergoglio o del saludo del Papa, sino que estas cuestiones están inmersas entre los actos comentados. Posiblemente, esto muestre que la misa era, en realidad, una de las actividades desarrolladas todos los años, quizás tan importante como la movilización al santuario, por ejemplo. Así, la insistencia de los dos grandes diarios por lo religioso parece encerrar un interés que liga la Iglesia al Estado, dado el énfasis que se coloca en el señalamiento a las responsabilidades políticas. A su vez, los vaivenes en la relación entre estas dos instituciones suelen influir en las publicaciones de los periódicos.

Ahora bien, al observar comparativamente las representaciones de los actos conmemorativos en los periódicos, observamos interesantes puntos de contacto. En primer término, la importancia de las fechas, los aniversarios resultan momentos propicios para recordar y para pedir justicia, los diarios enfatizan la cantidad de meses y años que pasaron. En los dos casos colocan más atención en 2005 y en 2014, por tratarse del primer y el décimo aniversario respectivamente. Esto responde, sin dudas, a que también en estas fechas hubo más organización y reclamo de parte de los miembros del Movimiento Cromañón, como sucede con las llamadas "fechas redondas" en otros eventos trágicos. En segundo lugar, puede afirmarse que la prensa representa las conmemoraciones a través del texto (donde puede aparecer el fragmento de una homilía, las palabras del familiar de una víctima fatal o un documento leído en un acto) pero también de la imagen, de las fotografías. En tercer término, un recurso común utilizado por los diarios para referirse a los actos de homenaje es la reseña (aunque en el caso de Página/12 se acerca más a la crónica por su observación detallada y su Histórico do artigo: 
RELACult - Revista Latino-Americana de Estudos em Cultura e Sociedade

Revista Latinoamericana de Estudios en Cultura y Sociedad | Revue Latino-américaine d'Études sur la culture et la société |

análisis), que frecuentemente alude al pasado pero también puede referirse al futuro en modo de anuncio, a veces son cuadros que funcionan como agenda y en otras ocasiones solamente se menciona lo que se desarrolla. La cuarta cuestión se liga a que la gran mayoría de los actos mencionados tienen lugar en la Ciudad Autónoma de Buenos Aires, distrito desde donde se editan estos periódicos, seguramente porque el boliche se situaba allí y los principales homenajes ocupan espacios públicos porteños, no obstante, en diferentes lugares del Conurbano bonaerense, en otras ciudades e incluso en otras provincias se han realizado conmemoraciones, debido a que un gran porcentaje de los afectados en el incendio vivían fuera de CABA. En este sentido, posiblemente Página/12 logre mostrar una heterogeneidad mayor de actos, aunque no atiende puntualmente a la cuestión geográfica.

En cuanto a las herramientas que fabrica el periódico para conmemorar Cromañón, que son insumos para la memoria, en Clarín hay notas que no aluden a los actos conmemorativos, se hallan, por una parte, 9 artículos que tocan las causas judiciales, las condenas, las indemnizaciones y otros aspectos jurídicos que también aparecen soslayadamente en otros textos. Sin embargo, cabe plantear algunas preguntas... ¿acaso las causas judiciales representaron verdaderas noticias al hablar de Cromañón?, ¿hubo avances o resultados significativos en los juicios?, ¿qué sentidos tiene hacer recurrentes menciones al tema judicial? Indudablemente, las grandes dimensiones de la masacre hicieron que se debieran desarrollar distintos juicios que involucran a miles de personas, no obstante, durante el período estudiado las condenas no quedaron efectivas, de hecho, en la actualidad el proceso penal no concluyó. En consecuencia, estos artículos que informan sobre la situación judicial de los acusados y dónde se encuentra cada uno, que comentan las expectativas de las distintas partes, que piensan en la indemnización que cobraría cada damnificado, son textos que buscan, de alguna manera, dialogar con los pedidos y los reclamos que hacen los miembros del Movimiento Cromañón cada aniversario, echar luz sobre el camino recorrido en materia judicial. No obstante, hay otros textos vinculados a las responsabilidades que están más consagrados a las tensiones políticas y son utilizados por el diario con fines específicos. Tal es el caso de dos de los artículos publicados el 31 de diciembre de 2014: en el primero, "Macri cruzó a Ibarra por sus acusaciones", recupera una especie de debate entre los dirigentes en relación con Cromañón; el segundo es una nota de opinión de Eduardo Paladini titulada "El 'príncipe' quiere volver", donde hace un recorrido por el desempeño de Aníbal Ibarra y lo critica duramente a través de un tono irónico y sarcástico. Estas notas, de cara al año electoral que estaba a punto de comenzar, muestran que Cromañón parece ser la excusa para hablar de cargos, postulaciones y pretensiones políticas, para hacer, en definitiva, campaña política. 
RELACult - Revista Latino-Americana de Estudos em Cultura e Sociedade

Revista Latinoamericana de Estudios en Cultura y Sociedad | Revue Latino-américaine d'Études sur la culture et la société |

Por otra parte, hay un conjunto de publicaciones que recuperan de distintas maneras las historias, las vidas, los recuerdos, las voces de padres, madres y sobrevivientes de Cromañón. Se trata de 11 artículos con diferentes características: una nota titulada "Juan llevó su carta de amor", publicada el 30 de diciembre de 2005, que cuenta que un hombre aprendió a leer y a escribir recientemente, confeccionó su primera carta para su hija y su esposa, fallecidas en Cromañón; una escueta columna titulada "Pensé en matarme", publicada el 31 de diciembre de 2005, que recupera algunas palabras de Patricio Fontanet, el cantante de Callejeros; una segunda columna titulada "Las flores de mi jardín", publicada el 31 de diciembre de 2006, que es un relato ficcional escrito por Raúl Morales, padre de Sofía Morales, fallecida en Cromañón; una nota que presenta el libro de Mariano Comínguez, sobreviviente del incendio, titulado "Relatos del ave fénix", que se encuentra en el centro de un artículo mayor publicado el 31 de diciembre de 2007; el 30 de diciembre de 2008 apareció “Ansiolíticos y antidepresivos", que menciona la historia de Silvina Gómez y Fabiana Puebla, dos mujeres sobrevivientes que perdieron a sus parejas en la masacre y continúan con un tratamiento médico y "Con el cuarto del hijo intacto", que recupera la dolorosa historia de Graciela Peloso y María Ester, madres que perdieron a sus hijos en Cromañón; "No sé si alguna vez llegaremos a cobrar" es el título de una nota del 30 de diciembre de 2009 donde presenta la historia de María Sol Urcullu y su familia, que no está estrechamente vinculada al resto de los textos de ese número que se consagran más a la parte judicial, aunque el título intente mostrar lo contrario; finalmente, en el décimo aniversario salió “Cromañón y después: 150 sobrevivientes todavía siguen el tratamiento", que habla de cinco sobrevivientes, "La angustia sin fin: fui con un amigo y volví sólo" sobre la pérdida que sufrió Facundo Nívolo, un sobreviviente, "El olor era exactamente el mismo que el de aquella noche", la historia de María Eugenia Macchi, una sobreviviente que ingresó nuevamente al boliche, éstas del 30 de diciembre 2014 y finalmente, el 31 de diciembre de 2014, el diario publicó "El dolor sin fin: los padres que murieron después de Cromañón".

Esta somera presentación permite ver que esta heterogeneidad de publicaciones que eligió mostrar el diario en algunos aniversarios contiene artículos que no hablan de los actos que se estaban llevando a cabo, ni de sucesos ocurridos en fechas cercanas al momento de enunciación, es decir, en general carecen del carácter novedoso e informativo que suelen tener muchas noticias. Entonces, ¿por qué el periódico presenta estas personas, estas historias o estas voces en los aniversarios? Podrían pensarse varias respuestas posibles, una de ellas es que es una de las formas que encuentra y escoge el grupo empresarial para referirse a Cromañón, para conmemorar un acontecimiento trágico sucedido 3, 4 ó 10 años atrás. Así, 
RELACult - Revista Latino-Americana de Estudos em Cultura e Sociedade

Revista Latinoamericana de Estudios en Cultura y Sociedad | Revue Latino-américaine d'Études sur la culture et la société |

trae el incendio al punto cero de la enunciación sin relatar exhaustiva y detalladamente lo que sucedió esa noche, que seguramente es conocido y recordado por el lector y que, además, probablemente esté reseñado en otra noticia, sino que busca o genera otros recursos para hablar de Cromañón, como puede ser la presentación de un libro o bien la historia de padres y sobrevivientes que siguen sufriendo las consecuencias de la masacre. En este caso, como puede observarse, Clarín prefiere recurrir al testimonio en un sentido amplio y complejo para conmemorar Cromañón, puesto que algunas notas recuperan frases de las personas, otras una imagen o simplemente algunos datos. Estos textos conservan, además, un tono dramático y cierta enunciación pasional que pueden conmover al lector. Indudablemente, amén de la conmemoración, el diario se ve en el desafío de pensar estrategias para hablar de un suceso pasado, éstas son variadas y parecen intentar capturar el interés del lector, en vez que presentar un abordaje novedoso o profundo de algún aspecto relevante en relación con el acontecimiento. Algunas de las características de estas notas podrían vincularse a la producción del nuevo periodismo surgido en Estados Unidos en los años sesenta, ya que combinan el drama realista ligado al dolor de quienes conmemoran, la historia que hace referencia a lo que sucedió la noche del incendio y la narrativa en torno a algunas experiencias y realidades de familiares y sobrevivientes.

Por último, cabe rescatar dos notas de opinión escritas por dos periodistas del diario, que representan, indudablemente, modos de entender y conmemorar Cromañón. Ambas fueron publicadas en los aniversarios más resonantes, el primero y el décimo. Así, el 31 de diciembre de 2005 se halla "Sorpresas y paradojas del fin de Año Viejo", un texto firmado por Marcelo A. Moreno repleto de ironías y sarcasmos, que reúne 6 noticias completamente distintas sobre acontecimientos desvinculados, aunque ligados por las sorpresas y repercusiones que despertarían. La primera tiene que ver con la intención del cantante del grupo de rock Callejeros, Patricio Fontanet, de volver a los escenarios, el autor toma sus declaraciones, que parecen haberlo indignado, y termina haciendo acusaciones a la banda. La otra nota de opinión más extensa es "Estertores de una década", un artículo de Pablo Sigal que selecciona y sintetiza distintos momentos importantes de esos diez años en el tema Cromañón, la mayoría ligados a la Justicia, con un soporte visual harto interesante: cinco tapas de diferentes ediciones de Clarín que destacaron esos momentos fundamentales para el diario. A la vez, intenta hacer un análisis de las significaciones de Cromañón más allá de la noche trágica, qué representa hoy esa palabra, aunque esta reflexión es brevísima y se diluye entre titulares y reseñas. En los dos casos, se trata de estrategias del periódico en las que se aleja del acontecimiento trágico para hablar de otras cuestiones que de él se desprenden, que no son acontérico do artigo:
Hition 
RELACult - Revista Latino-Americana de Estudos em Cultura e Sociedade

Revista Latinoamericana de Estudios en Cultura y Sociedad | Revue Latino-américaine d'Études sur la culture et la société |

analizadas sino presentadas a modo de punteo de temas o subtemas, que abren la puerta a posibles líneas de lectura ligadas a los procesos judiciales. En este sentido, puede pensarse que en realidad los juicios que se llevan a cabo después de un acontecimiento se constituyen como nuevos acontecimientos que la prensa trata particularmente, sin tener que volver al incendio en este caso.

Para conmemorar Cromañón, Página/12 acude fundamentalmente y en un primer momento al testimonio. En el corpus de notas hay textos que recuerdan Cromañón a través del relato de un sobreviviente, tal es el caso de "Relato de una sobreviviente", "Tener 20 años y ser sobreviviente" y "Voy caminando y lloro", tres artículos que salieron a la luz en las ediciones del 30 y el 31 de diciembre de 2005; "'Yo lo que quiero es curarme"”, “"No sabía cómo seguir viviendo"” y "'Nos hicieron sentir culpables", tres textos agrupados en una doble página del 31 de diciembre de 2006, que posee un gran título "Sobrevivientes" que presenta estas historias de vida. Por otro lado, el diario expone algunas notas que tocan y analizan cuestiones estrechamente ligadas a Cromañón pero que no se dedican a mirar el caso de un sobreviviente o una situación particular, sino que atienden a una problemática más general, entonces, Cromañón abre la puerta a pensar otras realidades. Tal es el caso del artículo publicado el 30 de diciembre de 2006 sobre la atención psicológica y las secuelas que conlleva el estrés postraumático desencadenado por una experiencia límite y traumática como Cromañón. Se titula "La atención debería prolongarse durante por lo menos tres años" y recupera la opinión del especialista Moty Benyakar. Otro ejemplo es el texto publicado el 31 de diciembre de 2007 bajo el título "Las discos porteñas son un umbral al infierno", que analiza la situación de múltiples locales nocturnos cuyos planos no coinciden con las características del lugar, sino que cuentan con innumerables irregularidades. Por último, se remarcan las notas de opinión o textos que analizan en un sentido amplio algún aspecto ligado a Cromañón, éstas representan probablemente el rasgo más importante que distingue al tratamiento propuesto por esta empresa de medios, que suele forjar este tipo de herramientas. Alterando un poco el orden de aparición, se encuentran: "Sin impunidad pero con deudas", un artículo del 30 de diciembre de 2005, donde Mario Wainfeld repasa diferentes funestos hechos criminales (desde los asesinatos de la última dictadura, pasando por María Soledad Morales, José Luis Cabezas, entre otros y finalizando en los chicos de Cromañón, sin que éstos clausuren la lista) y sus consecuentes reclamos, que implican deudas al poder político; un texto del mismo número titulado "La generación que busca sobrevivir", donde Eduardo Fabregat, periodista especialista en rock, mira las costumbres y los rituales del rock pero sobre todo piensa en los cambios que esta generación debe atravesar; el mismo autor el 30 de 
diciembre de 2007 escribió "Un escenarios sin escenarios", un texto que señala algunas situaciones post Cromañón como los inconvenientes que encuentran los grupos musicales para poder desarrollar un show; Fabregat el 30 de diciembre 2014 presenta otra nota de opinión que postula un conjunto de "Corrupciones", como versa el título, que compete a los funcionarios públicos pero también a los músicos y culmina invocando a la Justicia. Vale la pena detenerse en "No todo seguirá igual mañana", un artículo del 31 de diciembre de 2005 firmado por Luis Bruschtein, donde analiza lo que mostró Cromañón, la crisis de valores que atraviesa la sociedad y una extrema vulnerabilidad en la se hallan los jóvenes. Este texto con ciertos matices poéticos condensa un conglomerado de reflexiones que parten, como se señaló, de un análisis del estado de la cuestión, y se proyectan hacia un futuro que requerirá compromisos y esfuerzos para revertir la situación:

Sobre ese terreno sembrado de dudas, de buscar respuestas y soluciones que nunca darán seguridad ni satisfacción plena, de ausencias dolorosas pero irreversibles, lo cierto es que esta sociedad tiene una deuda con la juventud, que es no desentenderse y ofrecerle nuevamente la posibilidad de futuro (Página/12, 31/12/2005, p.4).

Es interesante señalar que en todos los casos, el diario se sirve del discurso del otro para conmemorar Cromañón, un sobreviviente, un padre, un músico, un médico o, como en estas últimas narraciones, un periodista que intenta analizar lo sucedido más allá del acontecimiento trágico que tuvo lugar en el pasado, a la inversa, distintos textos tratan de mirar reflexivamente el presente y proyectar un futuro que debería ser distinto. Esta manera de conmemorar Cromañón propone una construcción de memoria que supone tender puentes con otros sucesos trágicos y/o violentos, con otras realidades, pensar Cromañón desde el presente y mirando hacia el futuro, que es, en definitiva, una memoria que construye. Estas operaciones del diario que buscan mirar un acontecimiento pasado, que es Cromañón en este caso, resignificarlo en un tiempo presente con una apuesta explícita y firme en el futuro, muestran una mirada cabal que es a la vez social y política y dan cuenta del compromiso en las luchas por la memoria.

\section{Resultados y conclusiones}

Al final del recorrido surge el siguiente interrogante: ¿qué mostró este análisis bipartito de los textos? En principio, siguiendo los postulados de Jaramillo y Martín, la prensa escrita constituye un archivo de memoria que guarda, en este caso, ciertos actos conmemorativos que se celebraron durante los primeros 10 aniversarios para recordar Cromañón. Como todo archivo, requiere un proceso de selección que cada empresa va realizando, motivada por distintos intereses políticos, sociales y económicos. En esta representación de la conmemoración predomina la discursividad pero también hay imágenes, 
RELACult - Revista Latino-Americana de Estudos em Cultura e Sociedade

Revista Latinoamericana de Estudios en Cultura y Sociedad | Revue Latino-américaine d'Études sur la culture et la société |

fotografías que deben ser analizadas oportunamente. Como se ha visto, los periódicos se concentran en las actividades que se realizan tanto en Plaza de Mayo, espacio que no se vincula al incendio sino que es el emblema del reclamo de las Madres de Plaza de Mayo y de otros grupos defensores de los Derechos Humanos, como en el santuario del barrio de Balvanera, poniendo especial atención a la marcha que los moviliza de un lugar a otro visibilizando y haciendo oír los reclamos. Como marcan distintos investigadores, cada uno de estos espacios donde tienen lugar las conmemoraciones (la Plaza de Mayo, el santuario cercano al local y la peatonal, el Obelisco, etc.), adquieren múltiples usos y sentidos que los periódicos intentan analizar y mostrar. Ciertamente, cada empresa observa y destaca distintas cuestiones, así, mientras que Clarín se interesa notablemente por las celebraciones religiosas desarrolladas en la catedral porteña y por los dichos de diferentes sacerdotes, Página/l2 prefiere exponer otro acto paralelo e igualmente masivo que se organiza a unas cuadras de los homenajes centrales de cada año. En definitiva, observar qué muestra cada medio gráfico y cómo lo hace permite entender, en esta oportunidad, cómo ven Cromañón y cómo comprenden las conmemoraciones que se gestan en torno al incendio.

No obstante, además de las notas que aluden a los actos de homenaje, este archivo de memoria conserva otro conjunto de artículos que conmemoran Cromañón sin narrar los actos realizados sino produciendo otro tipo de insumos. En suma, podría afirmarse que Clarín conmemora Cromañón a través de artículos que recuperan historias de víctimas, familiares y sobrevivientes del incendio, que son quienes, asimismo, recuerdan y organizan los actos conmemorativos en cada aniversario. Como se explica aquí, se trata de insumos confeccionados por el diario que ponen en escena a distintos actores del Movimiento Cromañón, sin dar lugar precisa y necesariamente a lo que ellos quieren contar y manifestar. Del mismo modo, estas construcciones carecen de análisis y reflexiones que permitan volver a pensar Cromañón después de 4, 7 ó 10 años, sino más bien se apela a la pérdida, al trauma, a los reclamos y a las condenas, lo cual imposibilita conocer y construir memorias de Cromañón, dado que se lo presenta como un acontecimiento específico y particular del pasado. Como se ha visto, este suceso puntual y cerrado es utilizado también para realizar críticas a alguna figura o partido político y elogiar a otros. Página/12, por su parte, da a luz otros elementos más reflexivos y analíticos que proponen ir más allá de Cromañón, es decir, en primer término exhibe las historias y las voces de sobrevivientes que no han podido resolver ni superar el evento traumático, luego presenta artículos que observan alguna cuestión desencadenada por el incendio y notas de opinión que buscan reflexionar y hacer reflexionar sobre lo que muestra Cromañón, que es leer el acontecimiento trágico en un 
RELACult - Revista Latino-Americana de Estudos em Cultura e Sociedade

Revista Latinoamericana de Estudios en Cultura y Sociedad | Revue Latino-américaine d'Études sur la culture et la société |

tiempo presente y recordarlo pensando en el futuro, en quien intenta continuar sobreviviendo pero también en otras personas que podrían atravesar lo mismo, en situaciones o lugares que replicarían Cromañón. En general, tanto los actos conmemorativos recuperados por los periódicos como las herramientas que utilizan para recordar Cromañón (por ejemplo, los testimonios y las imágenes que se analizarán próximamente) confirman que los medios de comunicación conservan una mirada porteño-céntrica.

Ahora bien, si se observa someramente cómo aparece Cromañón en las notas publicadas pocas horas después de iniciado el incendio (CODARO, 2017), puede afirmarse que éstas representan el punto de partida de un conjunto amplio y diverso de textos que aparecieron los días, los meses y los años siguientes, que aquí son reducidas a un corpus delimitado que permita un análisis más profundo. En efecto, hay ciertas continuidades entre las primeras publicaciones de Cromañón y las que arribaron en los aniversarios, decisiones y lógicas periodísticas que muestran que las empresas se mantienen fieles a sus tradiciones y a sus estilos, son, en definitiva, determinadas formas de entender los sucesos, las realidades, las experiencias... en fin, la historia, que son propias de cada empresa y por ello se mantienen a través del tiempo y la distancia. Esto se observa en las primeras interpretaciones del incendio, en los temas que deciden tocar para hablar de Cromañón, en los homenajes que deciden contar, en las voces y los rostros que recuperan (y los modos que usan para hacerlo), etc. Sin dudas, estas lecturas e interpretaciones de Cromañón forman parte del posicionamiento ideológico de cada grupo empresarial en el espacio público. Clarín y Página/12 exhiben las formas de entender y desentrañar Cromañón, las responsabilidades y las consecuencias, que responden a la trayectoria y a la impronta ideológica de cada diario, tan distintivas y reconocidamente opuestas en distintos aspectos. Esoseguramente tendrá un impacto en el lector y en el imaginario social.

Por último, esto no parece agotarse en la revisión del corpus confeccionado ni en las comparaciones sino que los trabajos de otros investigadores permiten trazar otras líneas posibles de análisis. Como Hucowsky observa las configuraciones de "Evita" y "El Che", aquí podría analizarse, por ejemplo cómo aparecen los funcionarios, los músicos, los empresarios, los padres o los sobrevivientes. Asimismo, como proponen da Silva Catela y Diz, resultaría interesante analizar los vínculos que establece cada diario con los actos y los reclamos en torno a la última dictadura o, por qué no, en relación con otras acontecimientos similares como el incendio de la discoteca Kheyvis y a otros crímenes irresueltos como el asesinato de José Luis Cabezas, todas asociaciones que ya figuran en algunas notas. En fin, los artículos condensan innumerables significaciones que esta revisión no puede ni pretende 
RELACult - Revista Latino-Americana de Estudos em Cultura e Sociedade

Revista Latinoamericana de Estudios en Cultura y Sociedad | Revue Latino-américaine d'Études sur la culture et la société |

agotar. Por el contrario, las conmemoraciones son procesos que cambian, de igual manera sucede en la prensa escrita, cuyos modos de construcción de memoria van transformándose y adoptando nuevos y heterogéneos sentidos. Es trascendental reconocer la importancia que adquieren estos medios de comunicación en esta construcción de memoria dado que, en muchos casos, son los principales actores que siguen invitando a volver a mirar y hablar de Cromañón.

\section{Referencias}

BARBOSA, M. "Medios de comunicación y conmemoraciones. Estrategias de reactualización y construcción de la memoria". En Signo y Pensamiento, n³9, 2001. Recuperado de https://revistas.javeriana.edu.co/index.php/signoypensamiento/article/download/2946/2247

(Artículo).

CODARO, L. “Cromañón: la construcción del 'acontecimiento' en Clarín, La Nación y Página/12. En Question/Cuestión, 1(53), 219-235, 2017. Recuperado a partir de https://perio.unlp.edu.ar/ojs/index.php/question/article/view/3784 (Artículo)

DA SILVA CATELA, L. No habrá flores en la tumba del pasado. La experiencia de reconstrucción del mundo de los familiares de desaparecidos. La Plata: Ediciones Al Margen, 2001. (Obra completa)

"Derechos humanos y memoria. Historia y dilemas de una relación particular en Argentina". Texto presentado al VIII Congreso Argentino de Antropología Social, Salta 19 - 22 de septiembre de 2006. En el Simposio 21: Violencia, justicia y cultura política, 2008. Recuperado de https://periodicos.ufjf.br/index.php/TeoriaeCultura/article/view/12123/6355 (Ponencia)

DIZ, M. L. "Nunca más...un Cromañón: Las representaciones sociales del pasado dictatorial argentino en las fotografías de la prensa escrita del incendio en la discoteca Cromañón." Punto Cero, 15(21), 25-36, 2010a. Recuperado de http://www.scielo.org.bo/scielo.php?script=sci_arttext\&pid=S1815$\underline{02762010000200004 \& \operatorname{lng}=e s \& t \operatorname{lng}=e s}$. (Artículo)

. "El santuario de Cromañón: ¿templo o cementerio?" Revista Margen № 58, edición digital de Trabajo Social y Ciencias Sociales, 2010b. Recuperado de http://www.margen.org/suscri/margen58/diz.pdf (Artículo)

FERNÁNDEZ LÓPEZ, S. Reflejando políticas de conmemoración y memoria: los distintos aniversarios de Israel en la prensa. Madrid: Universidad Complutense de Madrid, 2012. Disponible en: https://eprints.ucm.es/21402/1/T34463.pdf (Tesis para optar por el grado de Doctor).

HUCOWSKY, S. G. Morir...mil veces morir. Acerca del modo de abordaje de la prensa escrita argentina, sobre la conmemoración de los aniversarios de las muertes de Eva Duarte y El Che Guevara. Universidad Nacional de Misiones. Facultad de Humanidades y Ciencias Sociales. Secretaría de Investigación y Postgrado. Maestría en Semiótica Discursiva, 2016. 
RELACult - Revista Latino-Americana de Estudos em Cultura e Sociedade

Revista Latinoamericana de Estudios en Cultura y Sociedad | Revue Latino-américaine d'Études sur la culture et la société |

Latin American Journal of Studies in Culture and Society

V. 07, $\mathrm{n}^{\circ}$ 01, jan.-abr., 2021, artigo ${ }^{\circ} 1932$ | claec.org/relacult | e-ISSN: 2525-7870

http://argos.fhycs.unam.edu.ar/bitstream/handle/123456789/676/TM_HUCOWSKY_2016.pd f?sequence $=1 \&$ is Allowed $=\mathrm{y}$ (Tesis de Maestría presentada para obtener el título de "Magíster en Semiótica Discursiva").

HUYSSEN, A. En busca del futuro perdido. Cultura y memoria en tiempos de globalización. México: Fondo de Cultura Económica, 2007. (Obra completa)

JELIN, E. Los trabajos de la memoria. Madrid: Siglo Veintiuno de España Editores, 2002. (Obra completa)

MARTIN, J.E. y JARAMILLO-MARIN, J. «Las conmemoraciones noticiosas en la prensa colombiana: rememorando la toma a Mitú". Palabra Clave [online]. vol.17, n.2, pp.378-411. ISSN 0122-8285, 2014. Recuperado de http://www.scielo.org.co/scielo.php?script=sci_abstract\&pid=S0122-

$\underline{82852014000200007 \& \operatorname{lng}=e n \& n r m=i s o \& t \operatorname{lng}=e s}$ (Artículo)

NORA, P. «L'ère de la conmémoration», Les lieux de mémoire, vol 3, 1992. (Obra completa) Paris: Gallimard.

PIPER SHAFIR, I. "La conmemoración como búsqueda de sentido", en REVISTA PLÉYADE 11/ ISSN: 0718-655X / ENERO - JUNIO/ PP. 1-11, 2013. Recuperado de http://132.248.9.34/hevila/PleyadeSantiago/2013/no11/1.pdf (Artículo)

PIPER, I. y ROJAS, B. (Eds.) Memorias, historia y derechos humanos (pp. 157-175). Santiago de Chile. Chile: Universidad de Chile, 2012. (Capítulo de libro)

RICOEUR, P. La memoria, la historia, el olvido. Buenos Aires: Fondo de Cultura Económica, 2008. (Obra completa)

ROUSSO, H. Le syndrome de Vichy de 1944 à nos jours. París: Le Seuil, 1987. (Obra completa)

VALDÉS, P. "Iniciativas de memoria: formas de representación y conmemoraciones en Argentina" en Belay, Raynald; Bracamonte, J., Degregori, C., I., Vacher, J.J. Memorias en conflicto: Aspectos de la violencia política contemporánea, Instituto Francés de Estudios Andinos, 2004. (Obra completa)

ZENOBI, D. Familia, política y emociones. Las víctimas de Cromañón entre el movimiento y el Estado. Ciudad Autónoma de Buenos Aires: Antropofagia, 2014. (Obra completa)

\section{FUENTES}

\section{Clarín}

"Revelación Nacional. 04", Clarín, 31 de diciembre de 2004 (primera edición).

"Más de 150 muertos en un boliche", Clarín, 31 de diciembre de 2004 (edición vespertina).

"'Me pisaron, pensé que no salía", Clarín, 31 de diciembre de 2004 (edición vespertina).

"El caso de la disco Kheyvis", Clarín, 31 de diciembre de 2004 (edición vespertina).

"La tristeza de las cosas perdidas" (tapa), Clarín, 30 de diciembre de 2005.

"Recuerdos perdidos. Nadie reclamó todavía muchos de los objetos hallados en Cromañón", Clarín, 30 de diciembre de 2005. 
"Una jornada de tristeza y luto envolvió a toda la ciudad", Clarín, 30 de diciembre de 2005.

"Juan llevó su carta de amor", Clarín, 30 de diciembre de 2005.

"El duelo infinito", Clarín, 30 de diciembre de 2005.

"Los números de la tragedia", Clarín, 30 de diciembre de 2005.

"Una multitud por el dolor de Cromañón" (tapa), Clarín, 31 de diciembre de 2005.

"Diez cuadras de dolor incontenible por los 194 chicos de Cromañón", Clarín, 31 de diciembre de 2005.

"Buenos Aires tiene que llorar y ser purificada por las lágrimas", Clarín, 31 de diciembre de 2005.

"Pensé en matarme", Clarín, 31 de diciembre de 2005.

"Una durísima amonestación”, Clarín, 31 de diciembre de 2005.

"Cientos de zapatillas en la avenida de Mayo", Clarín, 31 de diciembre de 2005.

"Justicia: cómo sigue la causa", Clarín, 31 de diciembre de 2005.

"Sorpresas y paradojas del fin del Año Viejo", Clarín, 31 de diciembre de 2005.

"Una misa y una marcha para recordar la tragedia de Cromañón", Clarín, 30 de diciembre de 2006.

"Carta de Chabán desde la cárcel", Clarín, 30 de diciembre de 2006.

"Homenaje a las 194 víctimas de Cromañón" (tapa), Clarín, 31 de diciembre de 2006.

"Críticas a Ibarra y a Kirchner en el segundo aniversario de Cromañón", Clarín, 31 de diciembre de 2006.

"Las flores de mi jardín", Clarín, 31 de diciembre de 2006.

"Vigilia en Plaza de Mayo por los muertos en Cromañón", Clarín, 30 de diciembre de 2007.

"Cromañón, a tres años, un dolor que no termina" (tapa), Clarín, 31 de diciembre de 2007

"La ciudad 'aún' no lloró a Cromañón”, Clarín, 31 de diciembre de 2007.

“Cromañón, cuatro años de puro dolor" (tapa), Clarín, 30 de diciembre de 2008.

"Cromañón: siguen en tratamiento psicológico 1 de cada 3 afectados", Clarín, 30 de diciembre de 2008.

"Ansiolíticos y antidepresivos", Clarín, 30 de diciembre de 2008.

"Con el cuarto del hijo intacto", Clarín, 30 de diciembre de 2008.

"Vigilia y marcha", Clarín, 30 de diciembre de 2008.

"Cromañón: misa y marcha a 4 años de la tragedia", Clarín, 31 de diciembre de 2008.

"Ya hay juicios por más de \$630 millones", Clarín, 30 de diciembre de 2009.

"Chabán y Callejeros, perfil bajo", Clarín, 30 de diciembre de 2009.

“"No sé si alguna vez llegaremos a cobrar", Clarín, 30 de diciembre de 2009.

"La causa penal, en espera", Clarín, 30 de diciembre de 2009.

"Bergoglio, duro con la Ciudad", Clarín, 31 de diciembre de 2009.

"Cromañón: los sueños de los que ya no están, en una muestra de fotos", Clarín, 30 de diciembre de 2010.

"Con condenados pero sin presos, decide Casación", Clarín, 30 de diciembre de 2010.

"Dolor y reclamo de justifica en Plaza de Mayo a 6 años de la tragedia de Cromañón", Clarín, 31 de diciembre de 2010.

"Reclamos, a siete años de Cromañón", Clarín, 31 de diciembre de 2011.

"Cromañón. Cómo viven tras las rejas los 14 condenados por la tragedia", Clarín, 30 de diciembre de 2012.

"La situación de todos los detenidos", Clarín, 30 de diciembre de 2012.

"Homenaje a ocho años del horror por Cromañón" (tapa), Clarín, 31 de diciembre de 2012.

"Cromañón: misa, fotos y globos para un homenaje menos amargo", Clarín, 31 de diciembre de 2012.

"Actos, música y una misa para recordar el noveno aniversario de Cromañón”, Clarín, 30 de diciembre de 2013. 
“Cromañón: el Papa les escribió una carta a los familiares de las víctimas”, Clarín, 31 de diciembre de 2013.

"Las idas y vueltas de la causa", Clarín, 31 de diciembre de 2013.

"Cromañón y después: 150 sobrevivientes todavía siguen en tratamiento", Clarín, 30 de diciembre de 2014.

"La angustia sin fin: 'Fui con un amigo al show y volví solo"”, Clarín, 30 de diciembre de 2014.

"Un diagnóstico que es un estigma más", Clarín, 30 de diciembre de 2014.

"'El dolor era exactamente el mismo que el de aquella noche", Clarín, 30 de diciembre de 2014.

"Los actos de hoy: misa, marcha y suelta de globos", Clarín, 30 de diciembre de 2014.

"Estertores de una década", Clarín, 30 de diciembre de 2014.

"Cromañón: emotivos actos para recordar a las víctimas", Clarín, 31 de diciembre de 2014.

"Macri cruzó a Ibarra por sus acusaciones", Clarín, 31 de diciembre de 2014.

“El 'príncipe' que quiere volver”, Clarín, 31 de diciembre de 2014.

\section{Página/12}

"Infierno en Once" (tapa), Página/12, 31 de diciembre de 2004.

"Trampa mortal en el Once", Página/12, 31 de diciembre de 2004.

"De bailanta a local multiuso", Página/12, 31 de diciembre de 2004.

"Yo no quiero esta pena en mi corazón" (tapa), Página/12, 30 de diciembre de 2005.

"Relato de una sobreviviente", Página/12, 30 de diciembre de 2005.

"Las marcas profundas de Cromañón”, Página/12, 30 de diciembre de 2005.

"La semana de la memoria", Página/12, 30 de diciembre de 2005.

"Sin impunidad pero con deudas", Página/12, 30 de diciembre de 2005.

"Donde hubo fuego, quedan controles", Página/12, 30 de diciembre de 2005.

"Misas, reclamos y una marcha", Página/12, 30 de diciembre de 2005.

"La generación que busca sobrevivir", Página/12, 30 de diciembre de 2005.

"Cruces entre Ibarra y la sala que lo está juzgando", Página/12, 30 de diciembre de 2005.

"Capital del dolor" (tapa), Página/12, 31 de diciembre de 2005.

"Repúblicas", Página/12, 31 de diciembre de 2005.

“"No se puede olvidar a Cromañón”", Página/12, 31 de diciembre de 2005.

"Los 1lantos en la Catedral", Página/12, 31 de diciembre de 2005.

"No todo seguirá igual mañana", Página/12, 31 de diciembre de 2005.

"'Tenemos algo de responsabilidad", Página/12, 31 de diciembre de 2005.

"Tener 20 años y ser sobreviviente", Página/12, 31 de diciembre de 2005.

"Voy caminando y lloro", Página/12, 31 de diciembre de 2005.

"Monitoreo de la jornada en Gobierno", Página/12, 31 de diciembre de 2005.

"Una pesadilla que no termina" (tapa), Página/12, 30 de diciembre de 2006.

"La atención debería prolongarse durante por lo menos tres años", Página/12, 30 de diciembre de 2006.

"Para muchos, la pesadilla aún no terminó", Página/12, 30 de diciembre de 2006.

"Subsidios para las víctimas", Página/12, 30 de diciembre de 2006.

"'Yo lo que quiero es curarme"”, Página/12, 31 de diciembre de 2006.

" "No sabía cómo seguir viviendo", Página/12, 31 de diciembre de 2006.

“"Nos hicieron sentir culpables"”, Página/12, 31 de diciembre de 2006.

"Las otras víctimas del fuego", Página/12, 30 de diciembre de 2007.

"La marcha de hoy", Página/12, 30 de diciembre de 2007.

"Un escenario sin escenarios", Página/12, 30 de diciembre de 2007. 
RELACult - Revista Latino-Americana de Estudos em Cultura e Sociedade

Revista Latinoamericana de Estudios en Cultura y Sociedad | Revue Latino-américaine d'Études sur la culture et la société |

"Los 194 ausentes" (tapa), Página/12, 31 de diciembre de 2007.

"Las discos porteñas son un umbral al infierno", Página/12, 31 de diciembre de 2007.

"Cinco mil voces para recordar tres años", Página/12, 31 de diciembre de 2007.

"La situación de los quince", Página/12, 31 de diciembre de 2007.

"Sobreviviendo a Cromañón", Página/12, 30 de diciembre de 2008.

"Un día para el recuerdo", Página/12, 30 de diciembre de 2008.

"Cuatro años y un dolor que no termina", Página/12, 31 de diciembre de 2008.

"Los sin techo, sin servicio de salud", Página/12, 31 de diciembre de 2008.

"Cromañón, parte dos", Página/12, 30 de diciembre de 2009.

“A cinco años del horror de Cromañón”, Página/12, 31 de diciembre de 2009.

"Un reclamo que se abre a otros reclamos", Página/12, 30 de diciembre de 2010.

"Bosque de la memoria", Página/12, 30 de diciembre de 2010.

"Homenaje por Cromañón”, Página/12, 30 de diciembre de 2012.

"Una jornada para cerrar ocho años", Página/12, 31 de diciembre de 2012.

"El grito de Cromañón" (tapa), Página/12, 30 de diciembre de 2013.

"El grito desgarrador de los nueve años”, Página/12, 31 de diciembre de 2013.

"Una peatonal de una década", Página/12, 30 de diciembre de 2014.

"Corrupciones", Página/12, 30 de diciembre de 2014.

"Diez años y una causa que aún sigue abierta", Página/12, 30 de diciembre de 2014.

“Audiencia convocada por Casación”, Página/12, 30 de diciembre de 2014.

"A diez años, Cromañón aún quema" (tapa), Página/12, 31 de diciembre de 2014.

"Cromañón, diez años, dos marchas", Página/12, 31 de diciembre de 2014.

"Puntos de vista", Página/12, 31 de diciembre de 2014.

As comemorações na imprensa escrita. Uma análise das notas do Clarín e da Página / 12 sobre Cromañón (Argentina)

Resumo 
Este artigo procura investigar alguns aspectos das comemorações do Cromañón, o incêndio ocorrido na Cidade Autônoma de Buenos Aires (Argentina) em 30 de dezembro de 2004 que deixou 194 mortos e milhares de sobreviventes, na imprensa escrita local. Tenta mostrar pontualmente como os jornais prestam contas dos atos, mas também produzem insumos para serem lembrados. Para isso, um corpus de artigos jornalísticos publicados no Clarín e no Página / 12, dois importantes jornais nacionais ideologicamente opostos, é formado nos dias $30 \mathrm{e}$ 31 de dezembro de 2005 a 2014 e os textos são lidos, descritos e analisados. Faz-se uma abordagem teórica das comemorações e, em primeiro lugar, estudam-se as representações dos atos comemorativos em cada um dos jornais e as ferramentas que produzem para a construção da memória, a fim de relembrar o Cromañón. Por fim, são apresentadas as conclusões e reflexões que decorrem deste trabalho, que servem para continuar a pesquisar em torno dele e a olhar para outros trágicos acontecimentos contemporâneos.

Palavras-Chave: Cromañón; Comemoração; Jornais; Memória.

\title{
Les commémorations dans la presse écrite. Une analyse des articles de Clarín et Página / 12 sur Cromañón (Argentine)
}

\section{Résumé}

Ce travail cherche à étudier certains aspects des commémorations de Cromañón, l'incendie qui s'est produit dans la ville autonome de Buenos Aires (Argentine) le 30 décembre 2004 et qui a fait 194 morts et des milliers de survivants, dans la presse écrite locale. Il essaie de montrer ponctuellement comment les journaux rendent compte des actes mais ils produisent également des intrants à retenir. Pour cela, on organise un corpus d'articles journalistiques publiés dans Clarín et Página / 12, deux grands journaux nationaux idéologiquement opposés, qui porte les textes publiés le 30 et 31 décembre 2004 sont lus, décrits et analysés. Ensuite, on fait une approche théorique aux commémorations : on étude, d'une part, les représentations des actes commémoratifs dans chacun des journaux et d'autre part, les outils pensés pour la construction de la mémoire, afin de se souvenir de Cromañón. Enfin, les conclusions et réflexions qui découlent de ce travail sont exposées, elles servent à poursuivre les recherches autour de cet événement tragique contemporain et d'autres événements tragiques contemporains.

Mots clés: Cromañón; Commémoration; Journaux; Mémoire.

\section{The commemorations in the written press. An analysis of Clarín and Página / 12's notes on Cromañón (Argentina)}

\begin{abstract}
This work seeks to investigate some aspects of the commemorations of Cromañon, the fire that occurred in the Autonomous City of Buenos Aires (Argentina) on December 30, 2004 that left 194 dead and thousands of survivors, in the local written press. It tries to show punctually how the newspapers give an account of the acts but also produce inputs to remember. For this, a corpus of journalistic articles published in Clarín and Página / 12, two important ideologically opposed national newspapers, is formed on December 30 and 31 from 2005 to 2014 and the texts are read, described and analyzed.. A theoretical approach is made to the commemorations and then, firstly, the representations of the commemorative acts in each of the newspapers and the tools they produce for the construction of memory are studied, in order to remember Cromañón. Finally, the conclusions and reflections that arise from this work are exhibited, which serve to continue researching around it and to look at other contemporary tragic events.
\end{abstract}

Keywords: Cromañón; Commemoration; Newspapers; Memory. 